\title{
Physical and chemical evaluation of the use of diesel composite fuel based on ricinic oil and bioethanol as fuel for diesel power plant
}

\author{
A.A. Sadov $^{1, *}$, L.A. Novopashin ${ }^{1}$, L.V. Denezhko ${ }^{1}$, and Yu.B. Cherkasov ${ }^{2}$ \\ ${ }^{1}$ Ural State Agrarian University, Department Technological and transport vehicles of the faculty of \\ engineering technology, 620075 Yekaterinburg, Russia \\ ${ }^{2}$ M. Dulatov Kostanay Engineering and Economic University, Department of Energy and Mechanical \\ Engineering, 59 Chernyshevskogo St., 110000, Kostanay, Kazakhstan
}

\begin{abstract}
The purpose of the article is to evaluate physical and chemical properties of mixtures based on ricinic oil and bioethanol, followed by determining the optimal concentrations of elements and the processing method. The study used methods for calculating the physical and chemical parameters of complex multicomponent mixtures with subsequent experimental verification of the accepted assumptions and hypotheses validity. The results of the study showed that heat treatment of ricinic oil by heating up to $330{ }^{\circ} \mathrm{C}$ allows for a chemical reaction of modification of ricinic oil (dehydration and splitting) in order to obtain products suitable for mixing with petroleum, and thanks to additional ultrasound treatment, it is possible to provide a higher degree of dispersion of emulsified products and increase the shelf life. The presented analytical method for evaluating and optimizing the physical and chemical properties of mixtures allows for preliminary optimization of their composition and excluding unsuitable mixtures for further research. Laboratory studies aimed at determining physical and chemical parameters of mixtures confirm the results of theoretical studies and according to the results, mixtures with a content of biological components of no more than $60 \%$ are identified, which correspond to the indicators of diesel fuel and are recommended for use.
\end{abstract}

\section{Introduction}

As a result of consideration of alternative fuels, from the point of view of economic and environmental feasibility, diesel composite fuel can be considered as the most promising for enterprises. In addition, unlike biodiesel, diesel composire fuel is closer to the physical and chemical properties of diesel fuel, which eliminates the expensive modernization of the main systems and mechanisms of the serial engine.

*Corresponding author: artemsadov@ya.ru 
As an additive to diesel fuel, oils of acclimatized crops that can be cultivated on the territory of the Russian Federation can be used, high-oilseed crops with high germination and yield such as rapeseed and castor-oil plant can be distinguished. These crops, in addition to obtaining oil from them, can also be used in agriculture as cattle feed. The most undervalued crop as a source of plant raw materials for DCF is castor-oil plant, with a high degree of oil content and yield. As a result of processing castor-oil plant fruits by cold pressing, about $10 \%$ of the oil remains in the residual meal, which can be isolated by processing the meal using extraction technology or processing the fruit by hot pressing to obtain technical ricinic oil with the possibility of using it as a raw material for obtaining paint and varnish materials, as well as diesel composite fuel

\subsection{Literature Review}

The chemical composition of ricinic oil is described by the formula $\mathrm{CH}_{3}-\left(\mathrm{CH}_{2}\right)_{5}-\mathrm{CH}$ $(\mathrm{OH})-\mathrm{CH}_{2}-\mathrm{CH}=\mathrm{CH}-\left(\mathrm{CH}_{2}\right)-\mathrm{COOH}$. These are 18-carbon atom fatty acids with a double bond between the ninth and tenth carbon atoms, also known as 12-hydroxy-oleic acid.

The main problem of using this oil as a source of biocomponent in DCF is poor miscibility with petroleum products, which is confirmed by foreign studies $[1,2,3]$. Since the physical and chemical properties of ricinic oil differ significantly from other oils due to the high content of ricinoleic acid. The properties of this vegetable component do not allow mixing the components directly in the DES power system, namely, the high oil viscosity; in order to reduce the viscosity, a three-component mixture of diesel fuel, ricinic oil and bioethanol is proposed in the work.

The resulting mixtures are subject to delamination and precipitation within a short period of time. To improve the quality of diesel mixed fuel during its storage and operation in order to ensure stabilization and homogenized structure, various mixing methods are used.

In this regard, it is advisable to evaluate the physical and chemical properties of mixtures based on ricinic oil and bioethanol, followed by determining the optimal concentrations of elements and the processing method.

In accordance with the objective set in the work, the following tasks were solved:

1. To determine theoretically and experimentally the effect of the element concentration and the processing method on the physical and chemical properties of the resulting composite fuel.

2. To develop a model for optimizing the mixture composition based on the physical and chemical parameters of the elements included in the mixture.

3. To determine theoretically and experimentally the degree of influence of the concentration of mixture elements on the physical and chemical properties.

\section{Materials and methods}

The research program was aimed at testing the possibility of using diesel composite fuel containing biological and mineral components with different concentrations based on ricinic oil and bioethanol in terms of physical and chemical properties.

Types of fuels studied in the work:

1. Diesel mineral commercial fuel of the Z-0,2-62 brand $-100 \%$ (hereinafter referred to as DF). 
2. Ricinic oil GOST $6757-96100 \%$ (hereinafter referred to as RicO) without and with pre-heat treatment.

3. Diesel composite fuel with the percentage of components: $90 \% \mathrm{DF}+5 \% \mathrm{RicO}+5 \%$ $\mathrm{Al} ; 80 \% \quad \mathrm{DF}+10 \% \quad \mathrm{RicO}+10 \% \quad \mathrm{Al} ; 70 \% \quad \mathrm{DF}+15 \% \quad \mathrm{RicO}+15 \% \quad \mathrm{Al} ; \quad 60 \% \quad \mathrm{DF}+20 \%$ $\mathrm{RicO}+20 \% \mathrm{Al} ; 50 \% \mathrm{DF}+25 \% \mathrm{RicO}+25 \% \mathrm{Al} ; 40 \% \mathrm{DF}+30 \% \mathrm{RicO}+30 \% \mathrm{Al}$.

\section{Research results}

Based on the known data [3-6], a promising method for processing ricinic oil by performing a modification reaction (dehydration and splitting) can can offered, since ricinolic acid is a thermosetting component.

We have proposed a method for modifying ricinic oil by heating the oil up to $330{ }^{\circ} \mathrm{C}$, but without using a solvent, for 5 minutes under vacuum with water splitting off from the remnants of ricinoleic acid.

According to this method, the technology for producing diesel composite fuel will look like this: ricinic oil is fed to a heat mixer, followed by heating to a temperature of $330{ }^{\circ} \mathrm{C}$, under vacuum inside the container, where additional oxidation occurs, followed by water separation. After 5 minutes of holding at a temperature of $330{ }^{\circ} \mathrm{C}$, the oil is pumped through a heat exchanger to cool to a temperature of $50^{\circ} \mathrm{C}$, excluding the boiling of alcohol and light fractions of diesel fuel. Cooled ricinic oil, diesel fuel and bioethanol are fed to a stationary mixer - dispenser, where the components are mixed in the required proportions. The resulting diesel composite fuel is pumped to the storage tank.

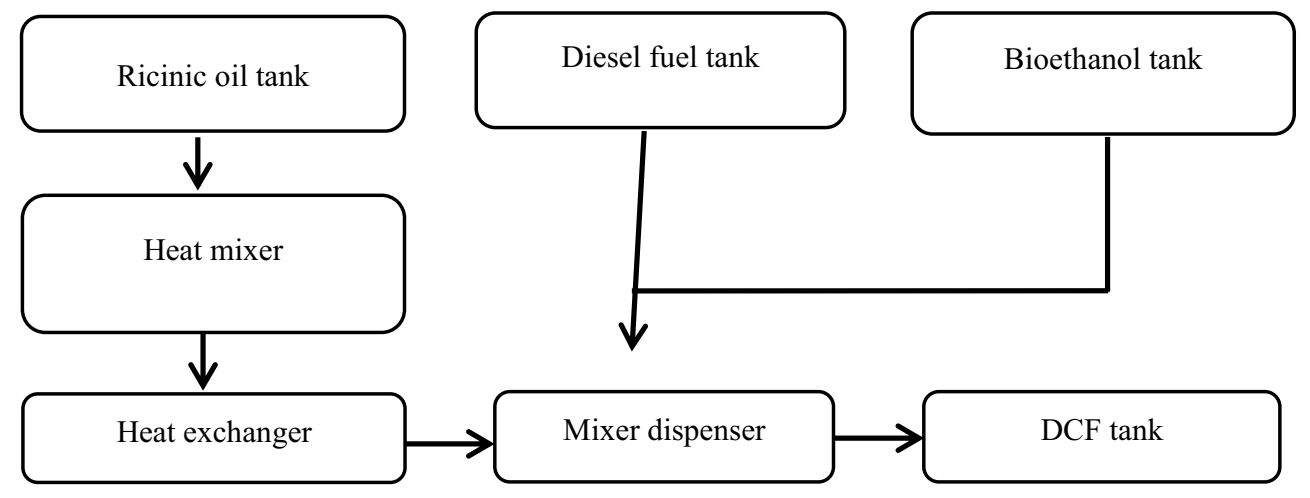

Fig. 1. Technology for producing diesel compound fuel from processed ricinic oil.

To evaluate the physical and chemical parameters of complex multicomponent mixtures, a calculation complex is proposed that allows a preliminary evaluation of the physical properties of the resulting mixture and determine its suitability as a fuel for a diesel engine.

Based on the works of scientists $[7,9,10,11,12]$, we have identified the physical and chemical parameters of fuel that affect the quality characteristics of fuel: cetane number, density, viscosity, and low-temperature properties.

In this paper, we have proposed a suitability coefficient $K_{S}$, which considers the optimization process based on the properties of the fuel used, which makes it possible to exclude unsuitable mixtures in further experimental studies.

To calculate the suitability coefficient аозможноthe use of the values of the mixture elements previously found out empirically by processing them according to the methods described below is provided. 
The suitability coefficient $K_{S}$ is formed as the ratio of the sum of three criteria of the fuel under study to the reference one. We take $J_{C N}$, the cetane number as the criterion for flammability, $J_{v}$ - the kinematic viscosity as the criterion for viscosity characteristics, and $J_{\rho}$ the density criterion as the density of the substance with the input of weight coefficients that characterize the significance of each of the terms:

The coefficient $S_{S}$ calculation can be written as:

$$
S_{S}=a_{C N} \cdot J_{C N}+a_{v} \cdot J_{v}+a_{\rho} \cdot J_{\rho}+a_{t} f=a_{C N} \cdot \frac{C N_{D F}}{C N_{i}}+a_{v} \cdot \frac{v_{i}^{20}}{v_{D F}^{20}}+a_{\rho} \cdot \frac{\rho_{i}}{\rho_{D F}}+\frac{e_{t}^{f}}{t_{a}+5}
$$

The weight coefficient $a_{C N}$ characterizing the flammability is assumed to be unity and the weighting coefficients $a_{v}, a_{\rho}, a_{t}^{f}$ characterizing the physical and chemical characteristics of the fuel were determined in three types of relationships are valid indicators of the tested fuel, $\left(e_{v}, e_{\rho}, e_{t}^{f}\right)$, to the limit acceptable values for the projected engine $\left(e_{v_{S p}}, e_{\rho S \mathrm{p}}\right)$ and limit fixed temperature of the ambient air in the region $\left(t_{a}\right)$

$$
\begin{aligned}
& a_{v}=\frac{e_{v}}{e_{v} S \mathrm{p}} \\
& a_{\rho}=\frac{e_{\rho}}{e_{\rho} S \mathrm{p}} \\
& a_{t}^{f}=\frac{e_{t}^{f}}{t_{a}+5}
\end{aligned}
$$

The suitability coefficient $K_{S}$ calculation can be written as:

$$
K_{S}=\frac{s_{S D F}}{S_{S_{i}}}
$$

We determined the optimal, less labor-intensive method of calculation, using the known cetane number of components with the lowest error of the result, according to the presented formula (6), set out in the works of A.N. Kartashevich [8].

The diesel fuel used has $\mathrm{CNDT}=49.6, \mathrm{CIDT}=50.8$. Cetane number of ricinic oil, according to data obtained by Emmanuel I. Bello, Adetokunbo Macapjiv Federal University of Technology, Minna, NIGERIA, is equal to $C N_{\text {Ric } O}=36$; the cetane number of bioethanol according to the literature [9] is 8 units. The cetane number of mixed fuels is calculated using the formula (6):

$$
C N_{\text {mix }}=C_{D F} \cdot C N_{D F}+C_{R i c O} \cdot C N_{R i c O}+C_{a l} \cdot C N_{a l}
$$

where $\mathrm{CN}_{\text {mix }}$ the cetane number of the resulting mixture; $\mathrm{C}_{\mathrm{DF}}, \mathrm{C}_{\mathrm{RicO}}, \mathrm{C}_{\mathrm{al}}$ - the concentration of elements in mixture; $\mathrm{CN}_{\mathrm{DF}}, \mathrm{CN}_{\mathrm{RicO}}, \mathrm{CN}_{\mathrm{al}}$ - cetane number of elements in the mixture. The optimal method for calculating the density for mixtures is indicated in the formula (7)

$$
\rho_{\text {mix }}=\frac{m_{1}}{\mathrm{v}_{1}}+\frac{m_{2}}{\mathrm{v}_{2}}+\frac{m_{3}}{\mathrm{v}_{3}}
$$

where $m_{1}, m_{2}, m_{3}$ - the mass of substances included in the mixture, $g ; V_{1}, V_{2}, V_{3}$ - the volume of substances included in the mixture, $\mathrm{cm}^{3}$.

To predict the viscosity of components mixture with known mixing fractions, it is possible to use the McCoul - Walter Wright method

To do this, first, it is necessary to transform the viscosity of substances using equation (8). 


$$
W_{x}=\log \left[\log \left(v_{x}+0.7\right)\right]
$$

where $v_{x}$ - the kinematic viscosity of the substance $x$, in $\mathrm{mm}^{2} / \mathrm{s}$, component $\mathrm{i}$, at temperature $t_{x},{ }^{\circ} \mathrm{C} ; W_{x}$ - the converted viscosity of the $x$ substance.

After that, it is needed to add the converted viscosities considering the weight fractions in the mixture (9):

$$
W_{\text {mix }}=F_{C} \cdot W_{c}+F_{D F} \cdot W_{D F}+F_{\mathrm{M}} \cdot W_{\mathrm{M}}
$$

where $F_{C}, F_{D F}, F_{\mathrm{M}}$ - the percentage of the component in the mixture, $\% ; W_{c}, W_{D F}, W_{\mathrm{M}}$ - the converted viscosity of the components.

After that, the viscosity index of the mixture $v_{\text {mix }}$ can be obtained by equation (10)

$$
v_{\text {mix }}=10^{10^{\text {Wmix }}}-0,7
$$

Laboratory studies were conducted to determine the effect of preparation methods and the composition of mixtures on the suitability as a fuel for physical and chemical parameters.

During laboratory studies, such indicators as density, viscosity and stability of the

\begin{tabular}{|c|c|c|}
\hline Type of test liquid & Measured value & measurement result \\
\hline Alcohol (Al) & \multirow{9}{*}{$\begin{array}{l}\text { Density, } \mathrm{g} / \mathrm{cm}^{3} \text { at } \\
20^{\circ} \mathrm{C}\end{array}$} & 0.80 \\
\hline Diesel fuel (DF) & & 0.83 \\
\hline Ricinic oil (RicO) & & 0.94 \\
\hline $\begin{array}{lll}40 \% & \mathrm{DF}+30 \% & \mathrm{RicO}+30 \% \\
\mathrm{Al} & & \\
\end{array}$ & & 0.854 \\
\hline $\begin{array}{lll}50 \% & \mathrm{DF}+25 \% & \mathrm{RicO}+25 \% \\
\mathrm{Al} & & \end{array}$ & & 0.85 \\
\hline $\begin{array}{lll}60 \% & \mathrm{DF}+20 \% & \mathrm{RicO}+20 \% \\
\mathrm{Al} & & \\
\end{array}$ & & 0.846 \\
\hline $\begin{array}{lll}70 \% & \mathrm{DF}+15 \% & \mathrm{RicO}+15 \% \\
\mathrm{Al} & & \\
\end{array}$ & & 0.842 \\
\hline $\begin{array}{l}80 \% \\
\mathrm{Al}\end{array}$ & & 0.838 \\
\hline $90 \% \mathrm{DF}+5 \% \mathrm{RicO}+5 \% \mathrm{Al}$ & & 0.834 \\
\hline
\end{tabular}
resulting mixtures were determined.

Table 1. Results of the mixtures density determination

According to the conducted laboratory studies of the mixtures density, there were no deviations from the scientifically based optimal values of the fuel density indicators used in

\begin{tabular}{|c|c|c|}
\hline Type of test liquid & Measured value & measurement result \\
\hline Alcohol (Al) & \multirow{6}{*}{$\begin{array}{c}\text { Kinematic viscosity, } \\
\mathrm{mm}^{2} / \mathrm{s}, \\
\text { at } 20^{\circ} \mathrm{C}\end{array}$} & 1.52 \\
\hline Diesel fuel (DF) & & 2.13 \\
\hline Ricinic oil (RicO) & & 120.5 \\
\hline $40 \% \mathrm{DF}+30 \% \mathrm{RicO}+30 \% \mathrm{Al}$ & & 3.96 \\
\hline $50 \% \mathrm{DF}+25 \% \mathrm{RicO}+25 \% \mathrm{Al}$ & & 3.54 \\
\hline $60 \% \mathrm{DF}+20 \% \mathrm{RicO}+20 \% \mathrm{Al}$ & & 3.17 \\
\hline
\end{tabular}
internal combustion engines, which are in the range of $830-860 \mathrm{~kg} / \mathrm{m}^{3}$.

Table 2. Results of the mixtures viscosity determination by the falling-ball method 


\begin{tabular}{|c|c|}
\hline $70 \% \mathrm{DF}+15 \% \mathrm{RicO}+15 \% \mathrm{Al}$ & 2.9 \\
\hline $80 \% \mathrm{DF}+10 \% \mathrm{RicO}+10 \% \mathrm{Al}$ & 2.58 \\
\hline $90 \% \mathrm{DF}+5 \% \mathrm{RicO}+5 \% \mathrm{Al}$ & 2.34 \\
\hline
\end{tabular}

According to the conducted laboratory studies of viscosity, all mixtures correspond to the viscosity of scientifically based optimal indicators of the viscosity characteristics of fuel used in internal combustion engines, within the limits of 3...6 cSt for summer operation, and $1.8 \ldots 5 \mathrm{cSt}$ for winter.

Table 3. Results of the solidification temperature determination ${ }^{\circ} \mathrm{C}$

\begin{tabular}{|c|c|c|}
\hline Type of test liquid & Measured value & Solidification temperature ${ }^{\circ} \mathrm{C}$ \\
\hline Alcohol (Al) & \multirow{9}{*}{ Temperature, ${ }^{\circ} \mathrm{C}$} & -114.3 \\
\hline Diesel fuel (DF) & & -32 \\
\hline Ricinic oil (RicO) & & -18 \\
\hline $40 \% \mathrm{DF}+30 \% \mathrm{RicO}+30 \% \mathrm{Al}$ & & -38 \\
\hline $50 \% \mathrm{DF}+25 \% \mathrm{RicO}+25 \% \mathrm{Al}$ & & -56 \\
\hline $60 \% \mathrm{DF}+20 \% \mathrm{RicO}+20 \% \mathrm{Al}$ & & -49 \\
\hline $70 \% \mathrm{DF}+15 \% \mathrm{RicO}+15 \% \mathrm{Al}$ & & -42 \\
\hline $80 \% \mathrm{DF}+10 \% \mathrm{RicO}+10 \% \mathrm{Al}$ & & -36 \\
\hline $90 \% \mathrm{DF}+5 \% \mathrm{RicO}+5 \% \mathrm{Al}$ & & -34 \\
\hline
\end{tabular}

The results of the pour test show that all mixtures meet this requirement and have a pour point of about $-34^{\circ} \mathrm{C}$, which indicates the low-temperature properties of mixtures obtained on the basis of winter diesel fuel, bioethanol and ricinic oil. It should be noted that this indicator is greatly influenced by the presence of bioethanol.

Results of laboratory studies to evaluate the stability and segregation resistance of the mixture, depending on the type of treatment and mixing method

Analyzing the results of table 4 studies, it can be said that the mechanical and ultrasonic mixing method is unsuitable, since the time to delamination is less than 180 minutes. Heat treatment, which results in dehydration and splitting of ricinoleic acid, can increase the stability period to two months for a mixture of $90 \% \mathrm{DF}+5 \% \mathrm{RicO}+5 \% \mathrm{Al}$; at the same time, due to additional ultrasound treatment in comparison with mechanical mixing methods, it is possible to achieve a higher degree of dispersion of emulsified products, accelerate the process and improve the quality of the resulting emulsions. These conclusions are also confirmed by works $[12,13]$.

Table 4. Stability of mixtures

\begin{tabular}{|c|c|c|c|c|c|c|c|c|}
\hline \multirow[t]{4}{*}{ Test sample } & \multicolumn{8}{|c|}{ Method for components pre-treatment and mixing } \\
\hline & \multicolumn{2}{|c|}{$\begin{array}{c}\text { without } \\
\text { treatment } \\
\text { mechanical } \\
\text { mixing method }\end{array}$} & \multicolumn{2}{|c|}{$\begin{array}{l}\text { by ultrasound } \\
\text { followed by } \\
\text { mechanical } \\
\text { mixing }\end{array}$} & \multicolumn{2}{|c|}{$\begin{array}{c}\text { Heat treatment } \\
\text { followed by } \\
\text { mechanical mixing }\end{array}$} & \multicolumn{2}{|c|}{$\begin{array}{l}\text { Heat treatment } \\
\text { followed by } \\
\text { ultrasound } \\
\text { mixing }\end{array}$} \\
\hline & close & open & close & open & close & open & close & open \\
\hline & №1 & №2 & №5 & №6 & №7 & №8 & №9 & №10 \\
\hline $\begin{array}{l}40 \% \mathrm{DF}+30 \% \\
\mathrm{RicO}+30 \% \mathrm{Al}\end{array}$ & - & - & $\begin{array}{c}16 \\
\min \end{array}$ & $16 \mathrm{~min}$ & $40 \mathrm{~min}$ & $\begin{array}{l}40 \\
\min \end{array}$ & $\begin{array}{c}4 \\
\text { hours }\end{array}$ & $\begin{array}{c}4 \\
\text { hours }\end{array}$ \\
\hline $\begin{array}{l}50 \% \mathrm{DF}+25 \% \\
\mathrm{RicO}+25 \% \mathrm{Al}\end{array}$ & - & - & $\begin{array}{c}39 \\
\min \end{array}$ & $39 \mathrm{~min}$ & 120 hours & $\begin{array}{c}110 \\
\text { hours }\end{array}$ & $\begin{array}{c}720 \\
\text { hours }\end{array}$ & $\begin{array}{l}672 \\
\text { hours }\end{array}$ \\
\hline
\end{tabular}




\begin{tabular}{|l|c|c|c|c|c|c|c|c|}
\hline $\begin{array}{l}60 \% \mathrm{DF}+20 \% \\
\mathrm{RicO}+20 \% \mathrm{Al}\end{array}$ & $3 \mathrm{~min}$ & $3 \mathrm{~min}$ & $\begin{array}{c}120 \\
\mathrm{~min}\end{array}$ & $120 \mathrm{~min}$ & 210 hours & $\begin{array}{c}192 \\
\text { hours }\end{array}$ & $\begin{array}{c}816 \\
\text { hours }\end{array}$ & $\begin{array}{c}744 \\
\text { hours }\end{array}$ \\
\hline $\begin{array}{l}70 \% \mathrm{DF}+15 \% \\
\mathrm{RicO}+15 \% \mathrm{Al}\end{array}$ & $4 \mathrm{~min}$ & $4 \mathrm{~min}$ & $\begin{array}{c}122 \\
\mathrm{~min}\end{array}$ & $122 \mathrm{~min}$ & $\begin{array}{c}1296 \\
\text { hours }\end{array}$ & $\begin{array}{c}840 \\
\text { hours }\end{array}$ & $\begin{array}{c}1248 \\
\text { hours }\end{array}$ & $\begin{array}{c}960 \\
\text { hours }\end{array}$ \\
\hline $\begin{array}{l}80 \% \mathrm{DF}+10 \% \\
\mathrm{RicO}+10 \% \mathrm{Al}\end{array}$ & $4 \mathrm{~min}$ & $4 \mathrm{~min} \mathrm{DF}+5 \%$ \\
$\mathrm{RicO}+5 \% \mathrm{Al}$ & $6 \mathrm{~min}$ & $6 \mathrm{~min}$ & $\begin{array}{c}140 \\
\mathrm{~min}\end{array}$ & $140 \mathrm{~min}$ & $\begin{array}{c}1440 \\
\text { hours }\end{array}$ & $\begin{array}{c}840 \\
\text { hours }\end{array}$ & $\begin{array}{c}3096 \\
\text { hours }\end{array}$ & $\begin{array}{c}960 \\
\text { hours }\end{array}$ \\
\hline min & $180 \mathrm{~min}$ & $\begin{array}{c}1440 \\
\text { hours }\end{array}$ & $\begin{array}{c}840 \\
\text { hours }\end{array}$ & $\begin{array}{c}3576 \\
\text { hours }\end{array}$ & $\begin{array}{c}960 \\
\text { hours }\end{array}$ \\
\hline
\end{tabular}

Fig. 2. Emulsion structures obtained by mechanical mixing (left) and ultrasonic method (right)

In addition, the quantitative content of biocomponents has a significant impact on the shelf life. For example, a mixture of $40 \% \mathrm{DF}+30 \% \mathrm{RicO}+30 \% \mathrm{Al}$ has a stability period of 4 hours, and a mixture of $90 \% \mathrm{DF}+5 \% \mathrm{RicO}+5 \% \mathrm{Al}$ prepared with the same method -more than 3000 hours.

Also, the stability is influenced by the type of storage. We considered storage in a sealed container and open. From the presented data, it can be seen that the shelf life in a sealed container is twice as long as in an open one. This is due to the evaporation of alcohol and the oxidation of diesel fuel and ricinic oil.

\section{Conclusion}

1. The presented analytical method for evaluating and optimizing the physical and chemical properties of mixtures based on biological and mineral components allows for preliminary optimization of their composition and excluding unsuitable mixtures for further research.

2. Laboratory studies of the density of mixtures did not reveal deviations from the scientifically based optimal values of this indicator of fuel used in diesel internal combustion engines.

3. According to laboratory studies of the mixtures viscosity, we have identified mixtures with a content of biological components of no more than $60 \%$, which correspond to the optimal parameters of the viscosity characteristics of the fuel.

4. The results of laboratory studies show that all mixtures have a solidification temperature of about $-34^{\circ} \mathrm{C}$, which indicates good low-temperature properties of the mixtures.

5. Heat treatment of ricinic oil by heating up to $330{ }^{\circ} \mathrm{C}$ without the use of a solvent for 5 minutes under vacuum with water splitting from the remnants of ricinoleic acid allows a chemical reaction to modify the ricinic oil (dehydration and splitting) to obtain a less viscous drying ricinic oil suitable for mixing with petroleum products. Due to additional ultrasound treatment, it is possible to provide a higher degree of dispersion of emulsified products and increase the shelf life of more than six months compared to mechanical mixing methods. 


\section{References}

1. J. Saez-Bastante, S. Pinzi, F.J. Jimenez-Romero, M.D. Luque de Castro, F. PriegoCapote, Energy Conversion and Management, 96(1), 561-567 (2015)

2. G. Knothe, S.C. Cermak, R.L. Evangelista. Fuel, 96, 535-540 (2012)

3. H. Bateni, K. Karimi, A. Zamani, F. Benakashani. Applied Energy, 136, 14-22 (2014)

4. J. H. Saunders, K.K. Frisch. Chemistry of polyurethanes, (Moscow: Ed. Chemistry, 1968)

5. A.P. Gyulushanyan. Development of a method for increasing the polar properties of concomitant substances and technology for their removal from vegetable oils, Dis. Cand. Techn. Sciences, (Krasnodar, 2007)

6. H.V. Chetfield. Paint coatings, (M.: ed. Chemistry, 1968)

7. V.V. Ostrikov. Fuel, lubricants and technical fluids, Voronezh State Agrarian University n.a. Emperor Peter the Great, (Voronezh: 2017)

8. A.N. Kartashevich, S.A. Plotnikov, P.N. Cheremisinov. Bulletin of the Belarus State Agricultural Academy, 3, 144-146 (2017)

9. E. Bello, A. Makanju. Journal of Emerging Trends in Engineering and Applied Sciences, 2(3), 525-530 (2011)

10. V.A. Markov, V.M.P. Ramon, V.V. Biryukov. Izvestiya of HEI. Mechanical Engineering, 11(668), 39-52 (2015)

11. V.A. Markov, V.V. Biryukov, S.N. Devyanin. Transport on alternative fuel, 2(44), 18$28(2015)$

12. L. A. Novopashin, Yu. V. Pankov, L. V. Denezhko, S.E. Shcheklein, A. M. Dubinin, A. A. Sadov. Vegetable oils, fatty acids, and biodiesel: textbook, (Yekaterinburg: publishing house of the Ural SAU, 2020)

13. R.R. Gabitov, R.A. Usmanov, A.R. Gabitova, F.M. Gumerov. Bulletin of the Kazan Technological University, 9 (2012) 